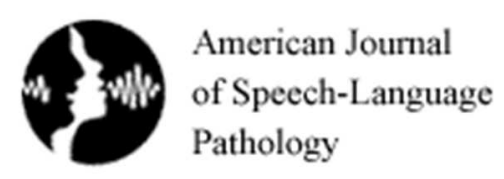

\title{
Computer and internet interventions to optimise listening and learning for people with hearing loss: accessibility, use and adherence
}

\begin{tabular}{|r|l|}
\hline Journal: & The American Journal of Audiology \\
\hline Manuscript ID: & AJA-14-0090.R1 \\
\hline Manuscript Type: & Research Forum \\
\hline Date Submitted by the Author: & 02-Apr-2015 \\
\hline Complete List of Authors: & $\begin{array}{l}\text { Ferguson, Melanie; Nottingham University Hospitals NHS Trust, NIHR } \\
\text { Nottingham Hearing Biomedical Research Unit } \\
\text { Henshaw, Helen; University of Nottingham, NIHR Nottingham Hearing } \\
\text { Biomedical Research Unit, }\end{array}$ \\
\hline Keywords: & $\begin{array}{l}\text { Hearing loss, Aural rehabilitation, Early intervention, Education, } \\
\text { Telepractice }\end{array}$ \\
\hline
\end{tabular}

\section{SCHOLARONE" \\ Manuscripts}


1 Computer and internet interventions to optimise listening and learning for people with

2 hearing loss: accessibility, use and adherence

3 Melanie Ferguson $\mathrm{PhD}^{1}$, Helen Henshaw $\mathrm{PhD}^{2}$

4

$5 \quad{ }^{1}$ NIHR Nottingham Hearing Biomedical Research Unit, Nottingham University Hospitals 6 NHS Trust, Nottingham UK

$7 \quad{ }^{2}$ NIHR Nottingham Hearing Biomedical Research Unit, Otology and Hearing Research

8 Group, Division on Clinical Neuroscience, University of Nottingham UK

9

10 Corresponding author:

11 Melanie Ferguson

12 NIHR Nottingham Hearing Biomedical Research Unit

$13 \quad 113$ The Ropewalk

14 Nottingham, UK

15 NG1 5DU

Tel: (+44)1158232619

Fax: (+44)115 8232615

20 Email: melanie.ferguson@nottingham.ac.uk 


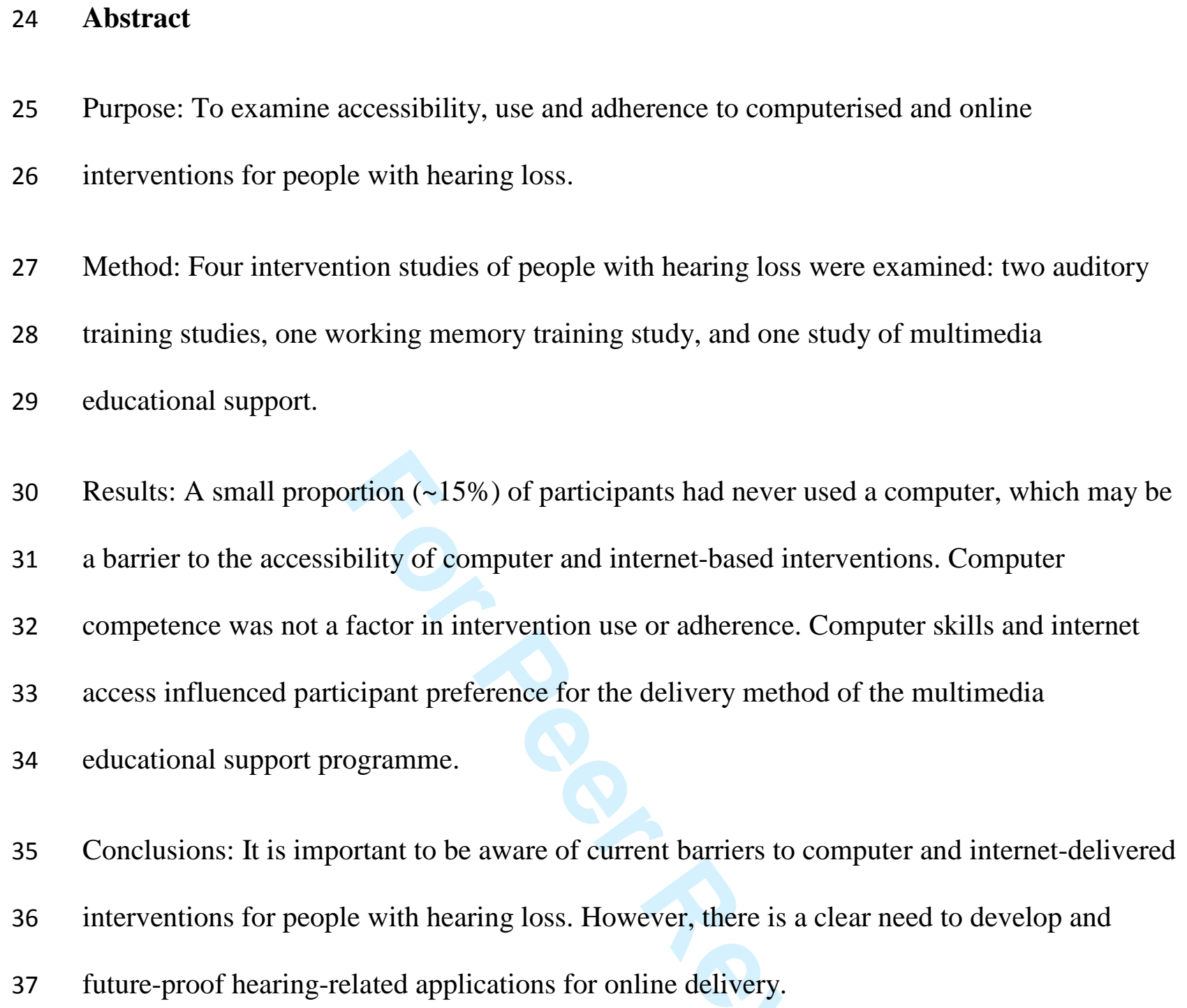

27 Method: Four intervention studies of people with hearing loss were examined: two auditory

28 training studies, one working memory training study, and one study of multimedia

30 Results: A small proportion $(\sim 15 \%)$ of participants had never used a computer, which may be

31 a barrier to the accessibility of computer and internet-based interventions. Computer

32 competence was not a factor in intervention use or adherence. Computer skills and internet

33 access influenced participant preference for the delivery method of the multimedia

34 educational support programme.

35 Conclusions: It is important to be aware of current barriers to computer and internet-delivered

36 interventions for people with hearing loss. However, there is a clear need to develop and

37 future-proof hearing-related applications for online delivery. 


\section{Introduction}

There is an ever increasing use of personal computers and the internet to provide healthcare and health-related information (Brouwer et al., 2011), and hearing healthcare is no exception.

Telehealth applications in audiology, or tele-audiology, include hearing screening (Smits, Merkus, \& Houtgast, 2006; Swanepoel, Myburgh, Howe, Mahomed, \& Eikelboom, 2014), diagnosis (Krumm, Ribera, \& Klich, 2007), and interventions such as auditory training (Ferguson, Henshaw, Clark, \& Moore, 2014; Sweetow \& Henderson Sabes, 2006), counselling (Laplante-Lévesque, Pichora-Fuller, \& Gagné, 2006; Lundberg, Andersson, \& Lunner, 2011) and patient education (Ferguson, Brandreth, Leighton, Brassington, \& Wharrad, In Review; Thorén, Öberg, Wänström, Andersson, \& Lunner, 2013). Advantages of tele-audiology include improved time-, clinical- and cost-effectiveness, and increased accessibility to healthcare (Fabry, 2010), with the added advantage of being delivered remotely in patients' homes (Ferguson et al., 2014; Henshaw \& Ferguson, 2013). A systematic review of peer-reviewed articles concluded that tele-audiology provided the potential to extend services beyond the audiology clinic, in particular to under-served communities and those with poor accessibility to audiology services (Swanepoel \& Hall, 2010).

Typically, discussions on accessibility of hearing healthcare and the benefits of teleaudiology focus on remote and rural communities in underdeveloped and developing countries, as well as those countries with large geographic distances, such as Australia. However, issues accessing hearing services are not limited to these countries, they are also relevant to smaller, developed countries, such as the UK (Ferguson, 2012). Firstly, it is estimated that only one in three people in the UK who would benefit from a hearing aid have one (AoHL, 2014). Secondly, many hearing aid users have significant hearing difficulties for at least ten years before they receive hearing aids (Davis, Smith, Ferguson, Stephens, \& 
64 Gianopoulos, 2007). Thirdly, there is a failure of family doctors to refer those in the pre-

65

66

67

68

69

70

71

72

73

74

75

76

77

78

79

80

81

82

83

84

85

86

87

typical hearing aid age group to audiology services. Just under half (47\%) of those with a significant hearing loss in the 55-74 year age group who went to their general practitioner with complaints of hearing loss failed to get an onward referral to audiology services (Davis, et al., 2007). Finally, two-thirds of the 10 million people with hearing loss in the UK are over the age of 65 years. Tele-audiology can only be effective if it is accessible, used and adhered to by the target population.

In the case of existing hearing aid users, it is important to be mindful of the skill set required to access personal computers (PCs), the internet, and mobile technologies without which access to tele-audiology solutions can be limited. We carried out a study of 50-74 year olds $(n=1298)$ and showed significant effects of age, gender and socioeconomic status (SES) on PC and internet use, with poorer use seen in older people, women, and those with lower SES (Henshaw, Clark, Kang, \& Ferguson, 2012). PC and internet use in the youngest group (5054 years) was $85 \%$ and $36 \%$ respectively but was significantly lower in the oldest group (7074 years) at $36 \%$ and $17 \%$. These differences were consistent with other reports (Seybert \& Lööf, 2010; Thoren, Öberg, Wänström, Andersson, \& Lunner, 2013). Current data on internet use shows a year-on-year increase in 55-74 year olds $(2010=61 \%, 2012=70 \%, 2014=$ $78 \%$ ), suggesting teleaudiology will become more prevalent in this age group (UNECE, 2015) over the coming years.

There has been little published on the effect of hearing loss on PC and internet use in older adults. In our study of PC and internet use (Henshaw et al., 2012), use was greater for those aged 63-74 years with slight hearing difficulties than those reporting no difficulties, although those with moderate hearing difficulties showed less use. This suggests that potential uses of tele-audiology in this age group, including early intervention such as auditory training, 
provision of education and support, and hearing screening, may be best served for those with milder hearing losses prior to obtaining hearing aids.

90 The main aim of this investigation was to examine accessibility, use and adherence with three different home-delivered interventions in older adults with hearing loss who had a broad range of computer skills.

\section{Methods}

94 Four studies are presented and assessed: two adaptive computerised auditory training with a control period (AT); computerised working memory training (WMT) with two arms, adaptive training and an active control (i.e. span stimuli were fixed at three items); multimedia educational support (MES) using reusable learning objects (RLOs), which are chunks of interactive multimedia learning, containing highly visual components to illustrate

WMT results are currently unpublished.

107 Computer skills were rated by participants on a validated three-category scale (Never used a computer, Beginner or Competent, see Henshaw et al., 2012). The percentage of participants in each category provides a measure of accessibility in terms of PC skills (Table 1). For the auditory training studies, the training program was demonstrated to the participants on a

111 laptop, which was then loaned for use at home. Use was reported as the mean training 
112 duration in minutes. Adherence was reported as percentage of total requested time on task

113 achieved, which was 360 and 210 minutes for AT1 and AT2 respectively. The working

114 memory training program was delivered online. Use was reported as the number of sessions

115 completed (35-45 minutes each), and adherence was reported as the percentage of

116 participants who completed all 25 sessions as requested. For all training intervention studies,

117 participants received a weekly telephone call from a researcher to monitor technical and

118 procedural issues. For the education study, participants were offered the choice of delivery

119 based on accessibility in their homes (DVD for TV or PC, or via the internet). Participants

120 were requested to watch each of the seven RLOs, and use was measured as the mean number

121 of RLOs watched. Adherence was the percentage who attended the six-week evaluation

122 session and watched all seven RLOs at least once.

123 Results

124 Accessibility, use and adherence results are shown in Table 1.

125 Auditory training. There was a broadly similar mix of computer skills across both studies,

126 with the Never category having the fewest participants $(\sim 15 \%)$. There was no significant

127 difference in use across categories ( $\mathrm{p}>.05$ ), suggesting that PC competence did not influence

128 the use of auditory training. Adherence was generally high, with no drop-outs for either

129 study. Adherence was similar for all categories in AT1 and not significant (p>.05).

130 Working memory training. All users were required to have internet access at home in order to 131 participate in the study, so by definition this intervention was not accessible to those without

132 internet access. There were twice as many Competent users as Beginners. Use was similar for 133 each category. Adherence was lower in the Competent users, but this was not significant (p > $134.05)$. There were however more drop outs for adaptive training $(n=4)$ than for active-control 
135 training $(\mathrm{n}=1)$, which may reflect the highly challenging nature of this type of training 136 intervention. Further examination of the effects of motivations and gameplay are required.

137 Multimedia educational support. The Never category had the smallest number of participants, similar to the auditory training studies. However, there were twice as many

Competent users than Beginners, not seen in the auditory training studies. This may be

because the MES study was carried out a few years later and so reflects the trend of increased PC and internet use over time (see UNECE, 2015). Despite a range of delivery modes, $21 \%$ of the patients were excluded from participating in the study because they did not have access to a DVD player, PC or internet. Use of the MES was greatest in the Never category, which $\mathrm{TV}$, although the reasons for this are not known.

\section{Discussion and Conclusion}

154 We have examined accessibility, use and adherence to three types of interventions for people 155 with hearing loss who have a range of computer skills. Accessibility is an inherent barrier to 156 interventions if either the person does not have either access to the hardware (e.g. DVD 157 player, PC or internet) or have the skills to use it. However, only a relatively small proportion 158 of the participants $(\sim 15 \%)$ had never used a computer. As our study participants were on 159 average younger than the typical first-time hearing aid user (74 years, Davis et al, 2007), 
160 accessibility is likely to be lower in a typical (older) UK hearing aid clinic sample.

161 Nevertheless, access to IT and mobile technologies for the over-55s is increasing, and will

162 continue to increase over the coming years (Deloitte, 2014). There was no evidence that PC

163 skill was a factor in either use or adherence with these interventions. It is possible that other

164 factors, such as individuals' extrinsic and intrinsic motivations to use these interventions, are

165 influential (Henshaw, McCormack, \& Ferguson, In press). In conclusion, the potential for

166 online applications to reach many people with hearing loss who cannot or will not access

167 conventional audiology services is substantial. Although there are currently some barriers to

168 internet access for a proportion of people with hearing loss, there is a clear need to develop

169 and future-proof internet-delivered applications.

\section{Acknowledgments}

171 We would like to thank our colleagues who made significant contributions to the intervention 172 studies - Dave Moore, Dan Clark, Ashana Tittle, Heather Wharrad, Marian Brandreth, Holly 173 Thomas, and William Brassington.

174 Conflicts of interest and source of funding: This paper presents independent research

175 funded by the National Institute for Health Research (NIHR) Biomedical Research Unit 176 Programme and the NIHR Research for Patient Benefit (RfPB) Programme (Grant Reference 177 PB-PG-0909-20294). The views expressed are those of the authors and not necessarily those 178 of the NHS, the NIHR or the Department of Health. The Nottingham University Hospitals 179 NHS Trust and University of Nottingham will receive a small proportion of any royalties 180 from the sale of the C2Hear RLOs. There will be no payment made to any individual member 181 of the research team. 
Table 1. Study and participant characteristics. Percentage, mean use and mean adherence of three categories of computer skills (Never, Beginner, Competent). $\mathrm{BEA}=$ better ear average, $\mathrm{HA}=$ hearing aid, RLOs = reusable learning objects, $\mathrm{TV}=$ television, PC-personal computer,

$\mathrm{Web}=$ internet

\begin{tabular}{|c|c|c|c|c|c|c|c|c|c|c|c|c|c|c|c|}
\hline & \multicolumn{3}{|c|}{ Auditory training 1} & \multicolumn{3}{|c|}{ Auditory training 2} & \multicolumn{3}{|c|}{ Working memory training } & \multicolumn{6}{|c|}{ Multimedia educational support } \\
\hline Study type & \multicolumn{3}{|c|}{ RCT } & \multicolumn{3}{|c|}{ Repeated measures } & \multicolumn{3}{|c|}{ RCT } & \multicolumn{6}{|l|}{ RCT } \\
\hline Intervention & \multicolumn{3}{|c|}{$\begin{array}{l}\text { Phoneme discrimination } \\
\text { in quiet }\end{array}$} & \multicolumn{3}{|c|}{$\begin{array}{l}\text { Phoneme discrimination } \\
\text { in noise }\end{array}$} & \multicolumn{3}{|c|}{$\begin{array}{l}\text { Verbal and Visuospatial } \\
\text { working memory and storage } \\
\text { tasks }\end{array}$} & \multicolumn{6}{|c|}{ Reusable learning objects } \\
\hline $\begin{array}{l}\text { Intervention } \\
\text { duration }\end{array}$ & \multicolumn{3}{|c|}{$\begin{array}{l}360 \text { minutes ( } 6 \text { hours) } \\
\text { across } 4 \text { weeks }\end{array}$} & \multicolumn{3}{|c|}{$\begin{array}{l}210 \text { minutes ( } 3.5 \text { hours) } \\
\text { across } 1 \text { week }\end{array}$} & \multicolumn{3}{|c|}{$\begin{array}{l}25 \text { sessions (approx.. } 16.5 \\
\text { hours) across } 5 \text { weeks }\end{array}$} & \multicolumn{6}{|c|}{7 RLOs $=58.7$ minutes across 6 weeks } \\
\hline $\begin{array}{l}\text { n participants } \\
\text { (n females) }\end{array}$ & \multicolumn{3}{|c|}{$44(15)$} & \multicolumn{3}{|c|}{$30(10)$} & \multicolumn{3}{|c|}{$57(30)$} & \multicolumn{6}{|c|}{$100(41)$} \\
\hline $\begin{array}{l}\text { Participants } \\
\text { (source of } \\
\text { recruitment) }\end{array}$ & \multicolumn{3}{|c|}{$\begin{array}{l}\text { Non-HA users } \\
\text { (general practitioner) }\end{array}$} & \multicolumn{3}{|c|}{$\begin{array}{l}\text { Existing HA users } \\
\text { (volunteer database) }\end{array}$} & \multicolumn{3}{|c|}{$\begin{array}{l}\text { Existing HA users } \\
\text { (volunteer database) }\end{array}$} & \multicolumn{6}{|c|}{$\begin{array}{l}\text { First-time HA users } \\
\text { (audiology service) }\end{array}$} \\
\hline $\begin{array}{l}\text { Age mean }(\mathrm{SD}), \\
\text { range in years }\end{array}$ & \multicolumn{3}{|c|}{$65.3(5.7), 53-74$} & \multicolumn{3}{|c|}{$67.4(7.1), 50-74$} & \multicolumn{3}{|c|}{$64.0(6.0), 50-74$} & \multicolumn{6}{|c|}{$68.8(9.2), 42-87$} \\
\hline $\begin{array}{l}\text { Mean } \mathrm{BEA}_{0.5-4 \mathrm{kHz}} \\
(\mathrm{SD}) \mathrm{dB} \mathrm{HL}\end{array}$ & \multicolumn{3}{|c|}{$32.5(6.0)$} & \multicolumn{3}{|c|}{$43.8(13.4)$} & \multicolumn{3}{|c|}{$42.6(13.88)$} & \multicolumn{6}{|c|}{$35.8(9.0)$} \\
\hline \multirow{3}{*}{$\begin{array}{l}\text { Data collection } \\
\text { period }\end{array}$} & \multicolumn{3}{|c|}{ 2009- 2011} & 2011 & 2012 & & 2012 & 2014 & 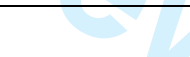 & 2012 & 2013 & & & & \\
\hline & $\%$ & $\begin{array}{c}\text { Use } \\
\text { (mins) }\end{array}$ & $\begin{array}{l}\text { Adherence } \\
(\%)\end{array}$ & $\%$ & $\begin{array}{l}\text { Use } \\
(\operatorname{mins})\end{array}$ & $\begin{array}{l}\text { Adherence } \\
(\%)\end{array}$ & $\%$ & $\begin{array}{c}\text { Use } \\
\text { (sessions) }\end{array}$ & $\begin{array}{c}\text { Adherence } \\
(\%)\end{array}$ & $\%$ & & $\begin{array}{l}\text { hoic } \\
\text { ivery }\end{array}$ & $\begin{array}{l}\text { of } \\
(\%)\end{array}$ & $\begin{array}{c}\text { Use } \\
\text { (RLO’s }\end{array}$ & $\begin{array}{c}\text { Adherence } \\
(\%)\end{array}$ \\
\hline & & & & & & & & & & & TV & $\mathrm{PC}$ & Web & & \\
\hline Never & 15.9 & 379 & $105 \%$ & 13.3 & 193 & 92 & 0 & - & - & 16.2 & 100 & 0 & 0 & 17.3 & 100 \\
\hline Beginner & 45.5 & 378 & $105 \%$ & 40.0 & 193 & 92 & 33.3 & 25.0 & 100 & 27.2 & 62 & 27 & 11 & 12.4 & 95 \\
\hline Competent & 38.6 & 380 & $106 \%$ & 46.7 & 203 & 97 & 66.7 & 23.3 & 87 & 56.6 & 24 & 16 & 60 & 11.9 & 96 \\
\hline
\end{tabular}




\section{References}

Action on Hearing Loss. (2014). Statistics about Deafness and Hearing. Retrieved 26th November 2014. http://www.actiononhearingloss.org.uk/your-hearing/aboutdeafness-and-hearing-loss/statistics.aspx.

Brouwer, W., Kroeze, W., Crutzen, R., de Nooijer, J., de Vries, N. K., Brug, J., \& Oenema, A. (2011). Which intervention characteristics are related to more exposure to internetdelivered healthy lifestyle promotion interventions? A systematic review. Journal of Medical Internet Research, 13(1), e22.

Davis, A., Smith, P., Ferguson, M., Stephens, D., \& Gianopoulos, I. (2007). Acceptability, benefit and costs of early screening for hearing disability: a study of potential screening tests and models. Health Technology Assessment, 11(42), 1-294.

Deloitte. (2014). The smartphone generation gap: over 55? There's no app for that. Retrieved 10th December 2014, from

http://www2.deloitte.com/content/dam/Deloitte/global/Documents/TechnologyMedia-Telecommunications/gx-tmt-2014prediction-smartphone.pdf

Fabry, D. (2010). Applications of telehealth for hearing care. Audiology Today, Sep, 18-25.

Ferguson, M. (2012). Delivery of hearing healthcare and education using the internet. ENT and Audiology News, 21(3), 68-69.

Ferguson, M., Brandreth, M., Leighton, P., Brassington, W., \& Wharrad, H. (in review). A randomised controlled trial to evaluate the benefits of a multimedia educational programme for first-time hearing aid users. Ear and Hearing.

Ferguson, M. A., Henshaw, H., Clark, D. P., \& Moore, D. R. (2014). Benefits of phoneme discrimination training in a randomized controlled trial of 50-to 74-year-olds with mild hearing loss. Ear and Hearing, 35, e11-e121. 
Henshaw, H., Clark, D., Kang, S., \& Ferguson, M. (2012). Computer skills and internet use in adults aged 50-74 years: influence of hearing difficulties. Journal of Medical Internet Research, 14(4), e113.

Henshaw, H., \& Ferguson, M. (2013). Working memory training for adult hearing aid users: study protocol for a double-blind randomized active controlled trial. Trials, 14(417), $1-10$.

Henshaw, H., McCormack, A., \& Ferguson, M. A. (In press). Intrinsic and extrinsic motivation drives computer-based auditory training uptake, engagement, and adherence for people with hearing loss. Frontiers in Auditory Cognitive Neuroscience.

Krumm, M., Ribera, J., \& Klich, R. (2007). Providing basic hearing tests using remote computing technology. Journal of Telemedicine and Telecare, 13(8), 406-410.

Laplante-Lévesque, A., Pichora-Fuller, M. K., \& Gagné, J.-P. (2006). Providing an internetbased audiological counselling programme to new hearing aid users: A qualitative study. International Journal of Audiology, 45(12), 697-706.

Lundberg, M., Andersson, G., \& Lunner, T. (2011). A randomized, controlled trial of the short-term effects of complementing an educational program for hearing aid users with telephone consultations. Journal of the American Academy of Audiology, 22(10), 654-662.

Seybert, H., \& Lööf, A. (2010). Internet usage in 2010 - households and individuals. Data in Focus, 50, 2010.

Smits, C., Merkus, P., \& Houtgast, T. (2006). How we do it: The Dutch functional hearingscreening tests by telephone and internet. Clinical Otolaryngology, 31(5), 436-440.

Swanepoel, D. W., \& Hall, J. W. (2010). A systematic review of telehealth applications in audiology. Telemedicine Journal and e-Health, 16(2), 181-200. 
Swanepoel, D. W., Myburgh, H. C., Howe, D. M., Mahomed, F., \& Eikelboom, R. H. (2014). Smartphone hearing screening with integrated quality control and data management. International Journal of Audiology, Early Online, 1-9.

Sweetow, R. W., \& Henderson Sabes, J. (2006). The need for and development of an adaptive listening and communication enhancement (LACETM) program. Journal of the American Academy of Audiology, 17(8), 538-558.

Thorén, E. S., Öberg, M., Wänström, G., Andersson, G., \& Lunner, T. (2013). Internet access and use in adults with hearing loss. Journal of Medical Internet Research, 15(5), e91.

Thorén, E. S., Öberg, M., Wänström, G., Andersson, G., \& Lunner, T. (2013). A randomized controlled trial evaluating the effects of online rehabilitative intervention for adult hearing-aid users. International Journal of Audiology, 53(7), 452-461.

UNECE (United Economic Commission for Europe) Statistical Database: Percentage of populaiton using internet by age, sex, variable, countyr and year.

http://w3.unece.org/pxweb/dialog/Saveshow.asp?lang=1. Accessed 1 $1^{\text {st }}$ April 2015. 